\title{
RESPON PERTUMBUHAN, DAN HASIL TANAMAN CABAI MERAH SISTEM TUMPANG SARI RUMPUT GAJAH, KUNYIT DAN BAWANG DAYAK DENGAN MENGGUNAKAN TEKNOLOGI INTENSIF DAN CARA BIASA
}

\author{
Budi Prastia ${ }^{1}$, Bela Putra ${ }^{2}$ \\ ${ }^{1}$ Program Studi Agroteknologi Fakultas Pertanian Universitas Muara Bungo \\ ${ }^{2}$ Program Studi Peternakan Fakultas Pertanian Universitas Muara Bungo \\ e-mail : ${ }^{1}$ prastiabudi_umb@yahoo.com
}

Artikel Diterima 18 November 2020, disetujui 10 Desember 2020

\begin{abstract}
ABSTRAK
Kendala utama rendahnya produksi cabai skala nasional adalah masih terbatasnya teknologi budidaya yang dimiliki akibat kurangnya informasi teknologi, sehingga perkembangan teknologi yang semakin maju memerlukan perbaikan atau modifikasi komponen teknologi budidaya yang sudah diterapkan petani untuk meningkatkan pendapatan. Tujuan penelitian ini adalah untuk mengetahui pengaruh paket teknologi budidaya tanaman intensif terhadap kesehatan pertumbuhan dan hasil cabai merah yang terlindung dari serangan hama. Penelitian ini menggunakan metode uji $\mathrm{T}$ untuk menguji dua variabel dengan 3 ulangan. Tabel yang digunakan untuk membandingkan uji statistik dan statistik aritmatika adalah tabel t. Paket teknologi budidaya cabai intensif yang ditumpangsarikan dengan tanaman kunyit, bawang Dayak dan rumput gajah. Hasil penelitian menunjukkan bahwa tinggi tanaman rumput gajah, tinggi tanaman kunyit, tinggi tanaman cabai merah, jumlah daun tanaman kunyit tidak berbeda nyata, tetapi berbeda pada jumlah rumpun. rumput gajah, tinggi tanaman Dayak, jumlah daun bawang Dayak, dan hasil cabai merah berbeda nyata. Sehingga dapat disimpulkan bahwa penerapan paket teknologi intensif lebih baik untuk tanaman pokok cabai merah tetapi untuk tanaman sela tergantung pada keawetan dan kesesuaian jenis tanaman yang diadopsi.
\end{abstract}

Kata kunci: cabai merah, kunyit, bawang dayak, rumput gajah, paket teknologi intensif, teknologi biasa

\begin{abstract}
The main obstacle to the low national scale production of chili is the limited cultivation technology that is owned due to a lack of technological information, so that increasingly advanced technological developments require improvements or modifications to existing cultivation technology components applied by farmers to increase income. The purpose of this study was to determine the effect of intensive crop cultivation technology packages on the health of growth and yield of red chilies which are protected from pests. The study used the T test method to test two variables with 3 replications. The table used to compare the test statistics and arithmetic statistics is the $t$ table. An intensive chilli cultivation technology package that is intercropped with turmeric plants, Kalimantan onions and elephant grass. The results showed that the height of the elephant grass plant, the height of the turmeric plant, the height of the red chili plants, the number of leaves of the turmeric plant, was not significantly different, but it was different in the number of clumps of elephant grass, the height of Dayak plants, the number of Dayak leeks, and the yield of red chilies real
\end{abstract}


difference. So the conclusion is that the application of an intensive technology package is better for red chili staple crops but for intercropping plants it depends on the durability and suitability of the types of plants adopted.

Keywords : red chilies, turmeric, Dayak onions, elephant grass, intensive technology packages, ordinary technology

\section{PENDAHULUAN}

Cabai merah (Capsicum annuum L.) merupakan salah satu komoditas hortikultura yang bernilai ekonomi tinggi. Akan tetapi dalam budidaya tanaman tersebut dijumpai kendala adanya serangan organisme pengganggu tumbuhan (OPT) yang dapat mengakibatkan kehilangan hasil yang cukup nyata dan merugikan. Hama-hama yang menyerang tanaman cabai merah, trips, dan kutudaun merupakan hama yang dominan. Serangan kedua hama tersebut bersama dengan tungau, ulat grayak, kutukebul, lalat buah, dan ulat buah yang dapat mengakibatkan kerusakan lebih dari 25\% (Setiawati et al. 2013; Prabaningrum \& Moekasan 2014).

Menurut Zulkifli AK, dkk, ( 2000 ) kendala utama penyebab rendahnya produksi cabai skala nasional adalah keterbatasan teknologi budidaya yang dimiliki karena kurangnya informasi teknologi. Pada umumnya petani masih menggunakan benih lokal yang ditanam terus menerus serta masih banyak komponen teknologi prapanen lainnya belum diterapkan secara tepat guna seperti pemupukan berimbang melalui akar, aplikasi PPC/ZPT melalui daun, pemeliharaan tanaman secara intensif, penggunaan mulsa plastik atau jerami, pengendalian hama/penyakit serta gulma.

Pendekatan pengelolaan tanaman secara terpadu (PTT) merupakan suatu upaya yang mampu memberikan produktivitas dan pendapatan petani yang optimal karena terjadinya efisiensi produksi (Syuryawati dan Faesal, 2014).
Perkembangan teknologi yang semakin maju menuntut perbaikan atau modifikasi

terhadap komponen teknologi yang sudah ada dan diterapkan petani untuk meningkatkan pendapatan ( Kariyasa dan Sinaga, 2004).

Pendapat Anggono. T.H., (2010). Sebagai usaha awal untuk melindungi tanaman adalah dengan menekan populasi hama, penyakit, dan gulma serendah mungkin sebelum kegiatan penanaman dimulai. Pada prinsipnya usaha perlindungan ini adalah untuk melindungi dan mencegah (preventif) kerusakan yang ditimbulkan oleh adanya jasad pengganggu tersebut, bukan untuk mengobati (kuratif). Pada kondisi normal, tanaman cabai diberi pestisida secara rutin sebagai tindakan preventif, pemberian dilakukan seminggu sekali dengan dosis ringan. Untuk tindakan kuratif penggunaan pestisida dilakukan dengan berbagai ketepatan, yaitu tepat jenis, dosis, waktu, dan cara penggunaan. Hama dan penyakit yang sering menyerang tanaman cabai, antara lain

Menurut Zulkifli AK,dkk, (2000) untuk melaksanakan intensifikasi cabai merah diperlukan rakitan teknologi sederhana yang mudah diadopsi petani dengan pertimbangan secara teknis mudah diterapkan, secara ekonomis menguntungkan, secara sosial budaya dapat diterima dan tidak merusak lingkungan. Paket teknologi yang dimaksud adalah pemilihan varietas, pengolahan tanah dan penggunaan mulsa, pemupukan melalui akar dan daun, pemangkasan/perempelan, pemberantasan hama, pemasangan ajir. Penggunaan paket teknolgi budidaya tanaman intensif diduga lebih berpengaruh dibandingkan cara teknologi biasa terhadap kesehatan, 
pertumbuhan dan hasil tanaman pokok cabe merah. Sistem tanam tumpang sari juga dapat menurunkan serangan hama dan penyakit dan lebih menguntungkan dibandingkan monokultur. Adapun tujuan dari penelitian ini ialah untuk mengetahui pengaruh paket teknolgi budidaya tanaman intensif terhadap kesehatan pertumbuhan dan hasil tanaman cabe merah yang terhindar dari hama penyakit. Sedangkan kegunaannya yaitu untuk memberikan sumbangsih dan pemikiran bagi pengguna atau petani cabe merah untuk menghindari serangan hama dan penyakit tanaman cabe merah dan menambah pengetahuan dalam mengelola tanaman cabe merah di lahan. Pendekatan paket teknologi tanaman secara intensif/terpadu (PTT) merupakan upaya yang mampu meningkatkan produktivitas dan pendapatan

petani karena terjadinya efisiensi produksi. Paket teknologi tanaman secara intensif adalah pendekatan dalam budi daya yang mengutamakan pengelolaan tanaman, lahan, air, dan organisme pengganggu tanaman (OPT) secara terpadu dan bersifat spesifik lokasi. Paket teknologi tanaman secara intensif bertujuan meningkatkan dan mempertahankan produktivitas tanaman secara berkelanjutan dan meningkatkan efisiensi produksi yang pengembangannya memperhatikan kondisi sumber daya setempat (Balitbangtan 2007; Balitbangtan 2008). Menurut Nurfalach, D. R., (2010) Teknik budi daya tanaman cabai meliputi tahapan: pengadaan benih, pengolahan tanah, penanaman, pemeliharaan tanaman, pengendalian hama dan penyakit, serta pemanenan.Permasalahan Penelitian

1. Apakah dengan penggunaan paket teknolgi budidaya tanaman intensif lebih berpengaruh dibanding cara biasa terhadap keragaan pertumbuhan dan hasil cabe merah.

2. Apakah dengan penggunaan paket teknolgi budidaya tanaman intensif dapat menurunkan serangan hama penyakit pada cabe merah.
3. Apakah sistem tanam tumpang sari dapat menurunkan serangan hama dan lebih menguntungkan dibandingkan monokultur dengan menghitung kesetaraan lahan.

\section{Wawasan dan Pemecahan Masalah}

Sulitnya teknik budidaya tanaman cabe merah bagi petani mendorong saya untuk meneliti bagaimana teknik budidaya cabai merah yang bisa menghasilkan pertumbuhan cabai merah yang optimal dan sehat, jika sudah mendapatkan pertumbuhan cabai merah yang optimal dan sehat maka hasil panen cabe merahpun akan bisa maksimal per satuan luas( $\mathrm{Ha}$ ). Untuk mendapatkan hal tersebut dilakukan pemecahan masalah dengan menerapkan paket teknologi intensif yang memasukan input teknologi budidaya dari awal pembenihan sampai akhir panen sebanyak mungkin dan seefisien yang bisa dilakukan, sehingga bisa mengatasi serangan hama dan penyakit yang selalu menyerang tanaman cabai yang diusahakan.

\section{Rumusan Tujuan Penelitian}

Adapun tujuan dari penelitian ini ialah untuk mengetahui pengaruh paket teknolgi budidaya tanaman intensif terhadap kesehatan pertumbuhan dan hasil tanaman cabe merah yang terhindar dari hama penyakit.

Sedangkan kegunaannya yaitu untuk memberikan sumbangsih dan pemikiran bagi pengguna atau petani cabe merah untuk menghindari serangan hama dan penyakit tanaman cabe merah.

\section{Rangkuman Tioritik}

\section{Tumpang Sari}

Tumpang sari adalah bentuk pola tanam yang membudidayakan lebih dari satu jenis tanaman dalam satuan waktu tertentu. Tumpang sari 
merupakan suatu upaya dari program intensifikasi pertanian dengan tujuan untuk memperoleh hasil produksi yang optimal, dan menjaga kesuburan tanah (Prasetyo, Inoriah, E., Sukardjo and Hesti , Pujiwati (2009).

Tumpang sari memiliki banyak keuntungan diantaranya mengurangi serangan hama dan penyakit, kemampuan adaptasi terhadap lingkungan, menyediakan kesinambungan dan variasi persediaan makanan, melindungi tanah dari erosi, pemamfaatan lahan yang lebih efektif, pemamfaatan tenaga kerja yang efisien, dan menghindari kegagalan usaha ( Wardhana, 2010 ).

Keberhasilan tumpang sari sangat ditentukan oleh kombinasi jenis-jenis tanaman penyusun. Kombinasi dua jenis tanaman yang umurnya tidak sama, kebutuhan cahaya matahari, $\mathrm{CO} 2$, air, dan unsur hara maksimum- masing jenis tanaman terjadi pada waktu berbeda bila kedua jenis tanaman tersebut ditanam pada waktu bersamaan ( Pramudayani, dkk., 2012 ).

Menurut Nurfalach, D.,R.,(2010)

Teknik budi daya tanaman cabai meliputi tahapan: pengadaan benih, pengolahan tanah, penanaman, pemeliharaan tanaman, pengendalian hama dan penyakit, serta pemanenan.

\section{Teknologi Intensif \\ Pengadaan Benih}

Bibit yang dibeli merupakan bibit yang siap tanam, umur bibit cabai sekitar 21 hari. Apabila menggunakan benih, benih yang dibutuhkan adalah 1 bungkus benih ukuran 10 gr.

\section{Pengolahan Tanah}

Mengolah tanah adalah untuk menciptakan sifat olah yang baik, dan sifat ini mencerminkan keadaan fisik tanah yang sesuai untuk pertumbuhan tanaman. Tujuan utama pengolahan tanah adalah menyediakan media tumbuh yang baik untuk kelangsungan hidup tanaman. Disamping itu pengolahan tanah dapat membantu memperbaiki drainase agar air mudah dialirkan, mngeluarkan racun dalam tanah dengan cara membalik tanah sehingga terjadi penguapan dan membunuh atau memotong siklus hidup gulma.

\section{Penanaman}

Bibit cabai yang akan ditanam yang telah berumur sekitar 21 hari dan telah berdaun 4-6 helai. Penyeleksian bibit perlu dilakukan sebelum dilakukan penanaman bibit. Hal ini dilakukan agar bibit yang ditanam benar-benar bibit yang sehat, normal dan vigor. Setelah bibit telah siap, bibit diambil secara hati-hati dan ditanam pada lubang yang telah dipersiapkan sebelumnya. Jarak lubang antar tanaman cabai yaitu $50 \times 70 \mathrm{~cm}$. Penanaman bibit cabai dilakukan pada saat sore hari, hal ini dilakukan karena apabila menanam bibit pada siang hari bibit yang masih muda akan kering dan mudah layu akibat sengatan matahari yang panas dan hal itu menyebabkan pertumbuhan bibit akan terganggu.

\section{Pemeliharaan Tanaman}

Setelah dilakukan penanaman, kegiatan selanjutnya adalah pemeliharaan. Bibit cabai yang telah ditanam dipelihara dengan baik hingga panen. Pada tahap ini diperlukan perhatian dan waktu luang untuk mengawasi dan memelihara tanaman. Jika tidak diikuti pemeliharaan yang tepat, kualitas tanaman cabai dipastikan akan menurun. Pemeliharaan tanaman cabai yang dilakukan meliputi penyiraman, penyulaman, pemasangan ajir, pewiwilan, pemupukan susulan, penyiangan serta pengendalian hama dan penyakit:

a. Penyiraman

Pada fase awal pertumbuhan atau saat tanaman cabai masih menyesuaikan diri terhadap lingkungannya (adaptasi), penyiraman perlu dilakukan secara rutin tiap hari. Penyiraman sebaiknya dilakukan pagi dan sore hari. Pada awal penanaman, setelah bibit ditanam tanaman disiram 
dengan air yang dicampur dengan urin kelinci. Urin kelinci digunakan karena urin kelinci merupakan salah satu pupuk cair yang mengandung kadar auksin yang lebih tinggi. Dalam sekali kocor menggunakan 2 liter urin kelinci. Penyiraman dilakukan pada pagi dan sore hari. Penyiraman dilakukan pada saat kondisi tanah tampak kering. Pada musim hujan, penyiraman tidak dilakukan secara rutin. Penyiraman dilakukan secukupnya sesuai dengan kebutuhan tanaman. Penyiraman bermanfaat untuk menjaga kelembapan tanah terjaga, agar tidak kekeringan dan pertumbuhan tanaman menjadi baik.

Menurut (Harpenas, 2010) penyiraman yang berlebihan pada musim hujan akan menyebabkan busuk pada akar dan memancing serangan cendawan akibat kelembapan yang terlalu tinggi. Sedangkan pada musim kemarau, frekuensi penyiraman ditingkatkan untuk menjaga ketersediaan air bagi tanaman.

b. Penyulaman

Penyulaman dilakukan apabila ada tanaman cabai yang ditanam mati. Penyulaman dilakukan pada waktu pagi hari. Bibit sisa penanaman awal digunakan sebagai pengganti tanaman yang telah mati, bibit yang digunakan untuk menyulam juga dipilih bibit yang sama agar pertumbuhannya dapat seragam. Penyulaman dilakukan paling lambat adalah 2 minggu setelah tanam. Adapun maksud dari penyulaman sendiri adalah untuk mengganti tanaman cabai yang telah mati agar tanaman cabai yang ditanam dapat seragam baik umur ataupun waktu panennya. Setelah bibit baru ditanam, bibit tersebut disiram agar bibit tidak layu dan mati.

\section{c. Pemasangan Ajir}

Pertumbuhan tanaman cabai sangat cepat. Pada saat tanaman telah besar, tanaman cabai tidak mampu menopang tubuh dan buahnya yang banyak. Oleh karena itu, perlu dilakukan pemasangan ajir untuk menopang tanaman cabai. Pemasangan ajir yang terlambat akan mengakibatkan kerusakan pada akar tanaman pada saat memasang (menancapkan) ajir. Pemasangan ajir menggunakan bahan dari bambu. Ajir dipasang dengan cara ditancapkan pada setiap lubang tanam. Batang tanaman diikat ke ajir dengan menggunakan tali rafia. Pemasangan ajir bertujuan agar tanaman tetap tegak dan untuk menyangga tanaman agar tidak

roboh pada saat tanaman berbuah lebat.

d. Pewiwilan

Pewiwilan perlu dilakukan pada tunas yang tumbuh pada ketiak yang berada dibawah cabang utama dan bunga pertama yang muncul pada cabang utama. Pewiwilan ini dilakukan agar pertumbuhan vegetatif tanaman dapat optimal. Pewiwilan dilakukan setelah tanaman berumur 2 minggu. Hal ini dilakukan agar tunas air tidak menyerap zat makanan yang terdapat pada tanah. Tetapi kegiatan tersebut belum dilakukan secara penuh karena keterbatasan tenaga kerja.

e. Pemupukan Susulan

Pemupukan susulan perlu diberikan pada tanaman cabai. Agar memacu pertumbuhan, baik pertumbuhan vegetatif maupun pertumbuhan generatif tanaman. Pemupukan susulan pada tanaman cabai dengan menggunakan pupuk daun Gandasil B, pupuk ini berbentuk kristal yang dilarutkan dalam air sehingga dapat diserap dengan mudah dan ditranslokasikan keseluruh bagian tanaman, pupuk ini mengandung unsur hara Nitrogen 6\%, Phospor 20\%, Kalium $30 \%$ dan Magnesium 3\%. Pemupukan dilakukan hanya sekali selama masa penanaman, pemupukannya pun dilakukan dengan sembarangan yaitu pada saat tanaman telah terserang hama dan penyakit sehingga pupuk daun yang diberikan tidak dapat bereaksi dengan baik dikarenakan pertumbuhan telah terhambat dan hal ini merupakan salah satu faktor kegagalan dalam penanaman tanaman cabai pada musim tersebut. Sedangkan pupuk kimia lain yang digunakan adalah pupuk NPK dengan dosis $3 \mathrm{~kg}$ diberikan pada saat tanaman berumur 9 HST dan 25 HST, 
NPK (nitrogen, phospor, dan kalium) merupakan pupuk majemuk (dalam satu pupuk mengandung beberapa jenis unsur hara) yang diperlukan tanaman dalam pertumbuhannya, pupuk NPK yang digunakan adalah pupuk NPK "Mutiara". ZA dengan dosis $6 \mathrm{~kg}$, pupuk ZA adalah pupuk kimia buatan yang dirancang untuk memberi tambahan hara nitrogen dan belerang bagi tanaman. Nama ZA singkatan dari zwavelzure ammoniak, yang berarti amonium sulfat (NH4 SO4). Pupuk ZA mengandung belerang 24\% dan nitrogen $21 \%$. $\mathrm{KCl}$ dengan dosis $3 \mathrm{~kg}$ diberikan pada saat tanaman berumur 54 HST.

f. Penyiangan

Penyiangan perlu dilakukan
sesegera mungkin apabila disekitar tanaman cabai yang ditanam sudah terlihat banyak gulma, yaitu pada antar bedengan. Hal ini dilakukan guna mencegah persaingan unsur hara antara tanaman cabai dengan gulma. Penyiangan dapat dilakukan dengan cara dicabut dengan tangan.

\section{g. Pengendalian Hama dan Penyakit}

Keberadaan hama dan penyakit di lahan sama-sama merugikan karena dapat menurunkan produksi tanaman cabai. Hama merupakan binatang yang merusak tanaman dan berukuran cukup besar sehingga dapat dilihat oleh mata telanjang. Adapun penyakit merupakan keadaan tanaman yang terganggu pertumbuhannya dan penyebabnya bukanlah binatang yang tampak oleh mata telanjang. Penyebab penyakit dapat berupa bakteri, virus, jamur, maupun gangguan fisiologis yang mungkin terjadi.

Penanganan dilakukan pada saat tanaman cabai telah terserang hama dan penyakit. Penanganan dilakukan dengan menggunakan pestisida Marshal dan Dithane M-45. Keterlambatan penanganan ini merupakan salah satu faktor penurunan kualitas cabai yang ditanam sehingga terjadi kegagalan

\section{BAHAN DAN METODE}

Bahan yang digunakan adalah bibit cabai merah jenis Kawat ( var.CA 237 ) yang telah di semai, Benih Bawang Dayak, Benih Kunyit dan benih rumput Gajah. Pupuk Kapur Dolomit, Pupuk kompos. pupuk daun, pestisida, furadan, banlate 45 , Round Up.

Alat yang digunakan meliputi cangkul, parang, meteran, mistar, timbangan, gembor, hands sprayer, alat tulis, kertas label.

\section{WAKTU DAN TEMPAT}

\begin{abstract}
Penelitian ini dilaksanakan di lahan Kebun percobaan Fakultas Pertanian, Universitas Muara Bungo. Kecamatan Batin III, Kabupaten Bungo. Dengan ketinggian tempat $110 \mathrm{~m} \mathrm{dpl}$, Jenis Tanah Ultisol. pH +-6. Memiliki bulan basah sekitar September, oktober, Desember, Januari dan Februari serta bulan kering sekitar bulan Maret, April, Mei, Juni, juli dan Agustus ( Morfologi Dusun Sungai Binjai, 2012 ).secara umum termasuk daerah beriklim tropis memiliki temperatur udara berkisar antara $27 \mathrm{C}^{\circ}-31$ C。, kelembaban $50 \%-80 \%$,
\end{abstract}

\section{RANCANGAN PERCOBAAN}

Penelitian menggunakan uji $\mathrm{T}$ untuk menguji dua variabel dengan 3 ulangan. tabel yang digunakan untuk membandingkan statistik uji dan statistik hitung adalah tabel t. Jadi untuk petak paket teknologi budidaya tanaman cabe terdapat 3 petak, setiap petak ada 4 tanaman maka jumlah tanaman pokok ( cabe ) berjumlah 12 tanaman, demikian juga untuk petak budidaya tanaman secara biasa dalam jumlah yang sama 12 tanaman. Setiap unit percobaan ada 3 sampel maka jumlah sampel tanaman cabe berjumlah 9 sampel. Untuk tanaman bawang Dayak setiap unit percobaan ada 4 tanaman jadi tiga petak maka tanaman berjumlah 12 tanaman dan untuk tanaman sampel setiap petak ada 2 tanaman sampel, 
jadi tanaman sampel keseluruhan ada 6 sampel. Untuk tanaman kunyit setiap petak ada 4 tanaman maka 3 petak berjumlah 12 tanaman,. Setiap petak ada 2 sampel sehingga jumlah keseluruhan ada 6 tanaman sampel. Masing- masing jenis tanaman dibuat petak percobaan yang ditanam secara monokultur untuk tanaman cabai, kunyit dan bawang kalimantan.

Faktor I : Paket teknologi budidaya cabei intensif yang ditumpang sari dengan tanaman kunyit, dan bawang kalimantan dan rumput gajah.

Faktor II : Budidaya tanaman cabai cara biasa tampa tumpang sari

\section{HASIL DAN PEMBAHASAN}

\section{Tinggi Tanaman Rumput Gajahh}

Hasil uji $t$ pada lampiran 3 diperoleh bahwa penggunaan paket teknologi tidak menunjukan beda nyata dibandingkan teknologi petani pengaruhnya terhadap tinggi tanaman rumput gajah.

Tabel 1. Tinggi Tanaman Cabai Merah ( dalam $\mathrm{cm}$ ) dengan menggunakan paket teknologi Intensif dibandingkan teknologi petani.

\begin{tabular}{|l|l|l|}
\hline $\begin{array}{l}\text { Tanaman } \\
\text { sampel }\end{array}$ & $\begin{array}{l}\text { Tek } \\
\text { intensif }\end{array}$ & $\begin{array}{l}\text { Tek } \\
\text { Petani }\end{array}$ \\
\hline 1 & 261 & 230 \\
\hline 2 & 146 & 196 \\
\hline 3 & 205 & 218 \\
\hline 4 & 170 & 213 \\
\hline 5 & 330 & 229 \\
\hline 6 & 170 & 171 \\
\hline 7 & 250 & 174 \\
\hline 8 & 304 & 178 \\
\hline 9 & 300 & 211 \\
\hline & & \\
\hline Total & 2136 & 1830 \\
\hline Rata-rata & 237,33 & 203,3 \\
\hline
\end{tabular}

Rumus uji t statistik adalah $\mathrm{t}=$ Ratarata X1 - Rata-reata X2

$\mathrm{S} \times 1-\mathrm{x} 2$

$\mathrm{T}$ hitung $=\underline{237,33-203,33}=$ 1,43

23,77

Tabel t significant $0,05 \%=2,101$

Kesimpulan : $\mathrm{t}$ hit $<\mathrm{t}$ tabel 0,05 hasil tinggi tanaman rumput gajah ternyata tidak berbeda nyata, hipotesis $\mathrm{H}_{0}$ ditolak maka hipotesis alternatif HA diterima.

Pada tabel 1 menunjukan bahwa penggunaan paket teknologi budidaya intensif dan teknologi budidaya petani memberikan tinggi tanaman yang sama pada tanaman rumput gajah. Diduga bahwa tanaman rumput gajah merupakan tanaman yang mempunyai respon dan adaptasi serta daya tahan yang kuat bila hidup di tanah ultisol dan iklim tropis, hingga walaupun ditumpang sari dengan tanaman lain seperti cabai merah, kunyit dan bawang dayak maka pertumbuhannya tingginya tetap memberikan kesamaan dengan teknologi petani yang tidak ditumpang sari.. Ditambah pula kesuburan tanah tempat penelitian yang telah diberi pupuk kompos dan buatan yang menambah unsur hara dalam tanah. Menurut Islami ( 1995) menyatakan salah satu faktor yang mempengaruhi pertumbuhan vegetatif tanaman yaitu kesuburan tanah. Pada keadaan tanah yang subur dengan banyak kandungan hara mineral, maka akar akan cenderung membentuk percabangan yang banyak. Penambahan pupuk buatan kedalam tanah seperti pupuk nitrogen, fosfor, kalium akan berpengaruh pada sistem perakaran.

\section{Jumlah Rumpun Tanaman Rumput Gajah}

Hasil uji $t$ pada lampiran 4 diperoleh bahwa penggunaan paket teknologi menunjukan beda nyata dibandingkan teknologi petani 
pengaruhnya terhadap jumlah rumpun tanaman rumput gajah. Hasil uji $t$ ditampilkan pada tabel 2 .

Tabel 2. Jumlah Rumpun Tanaman Rumput Gajah (dalam anakan) dengan menggunakan paket teknologi Intensif dibandingkan teknologi petani.

\begin{tabular}{|l|l|l|}
\hline $\begin{array}{l}\text { Tanaman } \\
\text { sampel }\end{array}$ & $\begin{array}{l}\text { Tek } \\
\text { intensif }\end{array}$ & $\begin{array}{l}\text { Tek } \\
\text { Petani }\end{array}$ \\
\hline 1 & 18 & 10 \\
\hline 2 & 16 & 16 \\
\hline 3 & 26 & 10 \\
\hline 4 & 24 & 11 \\
\hline 5 & 24 & 9 \\
\hline 6 & 17 & 7 \\
\hline 7 & 10 & 6 \\
\hline 8 & 27 & 7 \\
\hline 9 & 26 & 4 \\
\hline & & \\
\hline Total & 188 & 80 \\
\hline Rata-rata & 20,89 & 8,89 \\
\hline
\end{tabular}

Rumus uji t statistik adalah $\mathrm{t}=$ Ratarata X1 - Rata-reata X2

$\mathrm{S} \times 1-\mathrm{x} 2$

Thitung $=\frac{20,89-8,89}{2,69}=4,46$

Tabel t significant $0,05 \%=2,101$

Kesimpulan : t hit > t tabel 0,05 hasil jumlah rumpun tanaman rumput gajah ternyata berbeda nyata, hipotesis $\mathrm{H}_{0}$ diterima hipotesis Alternatif HA ditolak.

Jumlah rumpun rumput gajah dengan menggunakan paket teknologi intensif ternyata memberikan hasil yang lebih banyak dibandingkan menggunakan cara petani. Yaitu 20,89 dibanding dengan 8,89 anakan. Hal ini diduga dengan suburnya tanah yang diberi pupuk kandang dan pupuk kimia dapat mempercepat pertumbuhan rumpurt gajah sehingga setelah tiba pada ketinggian $1 \mathrm{~m}$ ( 2 bulan) tanaman sudah mempunyai akar yang banyak untuk menyerap unsur hara sehingga daun terbentuik banyak membuat laju foto sintesis tinggi sehingga dapat membentuk anakan yang banyak. Menurut Juergen S. Marassing, W. B. Kaunang, F. Dompas dan N. Bawole ( 2013 ) rumput gajah $d$ warf merupakan salah satu rumput unggul yang berasal dari Philipina dimana rumput ini mempunyai produksi dan kualitas yang cukup tinggi, menghasilkan rumpun anakan yang banyak dan mempunyai akar yang kuat, batang yang tidak keras dan struktur daun yang mudah sehingga sangat disukai oleh ternak.

\section{Tinggi Tanaman Kunyit}

Hasil uji $t$ pada lampiran 5 diperoleh bahwa penggunaan paket teknologi menunjukan tidak beda nyata dibandingkan teknologi petani pengaruhnya terhadap tinggi tanaman kunyit. Hasil uji t ditampilkan pada tabel 3.

Tabel 3. Tinggi Tanaman Kunyit ( dalam $\mathrm{cm}$ ) dengan menggunakan paket teknologi Intensif dibandingkan teknologi petani.

\begin{tabular}{|l|l|l|}
\hline $\begin{array}{l}\text { Tanaman } \\
\text { sampel }\end{array}$ & $\begin{array}{l}\text { Tek } \\
\text { intensif }\end{array}$ & $\begin{array}{l}\text { Tek } \\
\text { Petani }\end{array}$ \\
\hline 1 & 60 & 87 \\
\hline 2 & 45 & 66 \\
\hline 3 & 43 & 55 \\
\hline 4 & 32 & 58 \\
\hline 5 & 43 & 57 \\
\hline 6 & 74 & 66 \\
\hline 7 & 100 & 67 \\
\hline 8 & 68 & 74 \\
\hline 9 & 68 & 93 \\
\hline & & \\
\hline
\end{tabular}




\begin{tabular}{|l|l|l|}
\hline Total & 533 & 623 \\
\hline Rata-rata & 59,22 & 69,22 \\
\hline
\end{tabular}

Rumus uji $\mathrm{t}$ statistik adalah $\mathrm{t}=$ Rata$\underline{\text { rata X2 - Rata-rata X1 }}$

$$
\begin{aligned}
& \mathrm{S} \times 1-\mathrm{x} 2 \\
& \mathrm{X} 1=\sum \quad \underline{\mathrm{X}}_{1}=\underline{533}= \\
& 59,22 \\
& \underset{69,22}{\mathrm{X}_{2}}=\sum \quad \underline{\mathrm{X}}_{2}={ }^{\mathrm{N}_{1}}=\underline{623}= \\
& \mathrm{T}=\frac{\mathrm{N}_{2}}{13,59} \stackrel{9}{=}=0,74
\end{aligned}
$$

Tabel t significant $0,05 \%=2,101$

Kesimpulan : t hit $<\mathrm{t}$ tabel 0,05 hasil tinggi tanaman kunyit menggunakan paket teknologi intensif ternyata tidak berbeda nyata dengan teknologi petani maka, hipotesis $\mathrm{H}_{0}$ ditolak maka hipotesis alternatif diterima HA.

Penggunaan paket teknologi budidaya intensif secara statistik menunjukan hasil tinggi tanaman kunyit yang sama dibandingkan cara petani. Hal ini diduga syarat tumbuh tanaman kunyit tidak begitu memenuhi syarat atau belum ideal. Karena waktu penelitian digunakan pola tanam tumpang sari pada paket teknologi intensif sedangkan cara petani digunakan teknologi monokultur. Secara monokultur tentu saja ditempat terbuka dan langsung kena matahari, hal ini cocok dengan persyaratan tumbuh tanaman kunyit yang suka tempat terbuka dan sinar matahari langsung.

Pertumbuhan terbaik dicapai pada daerah yang memiliki curah hujan dan 1000-4000 mm/tahun. Tanaman kunyit menghendaki pengairan yang cukup maka system pengairan harus diusahakan cukup dan tertata baik. Tanaman ini dapat dibudidayakan sepanjang tahun. Pertumbuhan yang paling baik adalah pada penanaman awal musim hujan.

\section{Tinggi Tanaman Bawang Dayak}

Hasil uji $t$ pada lampiran 7 diperoleh bahwa penggunaan paket teknologi menunjukan beda nyata dibandingkan teknologi petani pengaruhnya terhadap tinggi tanaman bawang dayak. Hasil uji t ditampilkan pada tabel 5 .

Tabel 5. Tinggi Tanaman Bawang Dayak ( dalam $\mathrm{cm}$ ) dengan menggunakan paket teknologi Intensif dibandingkan teknologi petani.

\begin{tabular}{|l|l|l|}
\hline $\begin{array}{l}\text { Tanaman } \\
\text { sampel }\end{array}$ & $\begin{array}{l}\text { Tek } \\
\text { intensif }\end{array}$ & $\begin{array}{l}\text { Tek } \\
\text { Biasa }\end{array}$ \\
\hline 1 & 63 & 56 \\
\hline 2 & 67 & 66 \\
\hline 3 & 72 & 57 \\
\hline 4 & 73 & 67 \\
\hline 5 & 75 & 56 \\
\hline 6 & 80 & 59 \\
\hline 7 & 82 & 54 \\
\hline 8 & 75 & 65 \\
\hline 9 & 75 & 66 \\
\hline & & \\
\hline Total & 662 & 546 \\
\hline Rata-rata & 73,56 & 60,67 \\
\hline
\end{tabular}

Rumus uji t statistik adalah $\mathrm{t} \equiv$ $\underline{\text { Rata-rata X1 - Rata-rata X2 }}$

$$
\begin{aligned}
& \text { S x 1-x2 } \\
& \underset{73,56}{\mathrm{X} 1}=\sum \quad \underline{X}_{1}=\underline{662}= \\
& \mathrm{X}_{2}=\sum^{\mathrm{N}_{1}} \underline{\mathrm{X}}_{2}={ }^{9}=\underline{546}= \\
& 60,67 \\
& \mathrm{~T}=\frac{73,56-60,67}{2,612}=4,93
\end{aligned}
$$

Tabel t significant $0,05 \%=2,101$ 
Kesimpulan : t hit > t tabel 0,05 hasil tinggi tanaman bawang dayak ternyata berbeda nyata, hipotesis $\mathrm{H}_{0}$ diterima $\mathrm{HA}$ ditolak.

Tinggi tanaman bawang dayak dengan menggunakan paket teknologi intensif ternyata lebih tinggi dibandingkan teknologi petani. Hal ini diduga pengaruh berbagai teknik kegiatan yang dilakukan pada paket teknologi intensif lebih banyak antara lain pemupukan kompos, pengapuran, sistemtumpang sari,pemberian mulsa. Pada teknik petani tidak melakukan kegiatan tumpang sari ( hanya monokultur), tidak diberi mulsa, tidak diberi kapur pada tanah ( hanya diberi pupuk kandang dan kimia). Cahyaning R., ( 2019 ) hal ini disebabkan karena unsur hara yang terdapat didalam tanah sudah mencukupi untuk pertumbuhan tanaman terutama pada tinggi tanaman. Hal ini disebabkan karena pemberian pupuk kandang ayam kedalam tanah dapat meningkatkan ketersediaan unsur hara $\mathrm{N}$ yang sangat berpengaruh terhadap jumlah daun serta kandungan kalium yang berfungsi untuk meningkatkan fotosintesis sehingga berpengaruh terhadap vase vegetatif untuk merangsang pembentukan daun, dan akar.

\section{Hasil Panen Tanaman Cabai Merah}

Hasil uji $t$ pada lampiran 10 diperoleh bahwa penggunaan paket teknologi menunjukan beda nyata dibandingkan teknologi petani pengaruhnya terhadap hasil panen cabai merah pertanaman. Hasil uji t ditampilkan pada tabel 8

Tabel 8. Hasil Panen Tanaman Cabai Merah ( dalam gram ) dengan menggunakan paket teknologi Intensif dibandingkan teknologi petani.

\begin{tabular}{|l|l|l|}
\hline $\begin{array}{l}\text { Tanaman } \\
\text { sampel }\end{array}$ & $\begin{array}{l}\text { Tek } \\
\text { intensif }\end{array}$ & $\begin{array}{l}\text { Tek } \\
\text { Biasa }\end{array}$ \\
\hline 1 & 85 & 50 \\
\hline 2 & 80 & 45 \\
\hline 3 & 75 & 60 \\
\hline 4 & 55 & 45 \\
\hline 5 & 90 & 40 \\
\hline 6 & 65 & 45 \\
\hline 7 & 85 & 50 \\
\hline 8 & 180 & 45 \\
\hline 9 & 90 & 50 \\
\hline & & \\
\hline Total & 805 & 430 \\
\hline Rata-rata & 89,44 & 47,78 \\
\hline
\end{tabular}

\section{Cari t hitung}

Rumus uji t statistik adalah $\mathrm{t} \equiv$ $\underline{\text { Rata-rata X1 - Rata-rata X2 }}$

$$
\begin{aligned}
& \mathrm{S} \times 1-\mathrm{x} 2 \\
& \mathrm{X} 1=\sum \quad \underline{\mathrm{X}}_{1}=\underline{805}= \\
& 89,44 \\
& \mathrm{X}_{2}=\sum \stackrel{\mathrm{N}_{1}}{\underline{\mathrm{X}}_{2}}=\stackrel{9}{=} \underline{430}= \\
& 47,78 \\
& \begin{array}{ll}
\mathrm{N}_{2} & 9
\end{array} \\
& \mathrm{~T}=\frac{89,44-47,78}{12,06}=3,45
\end{aligned}
$$

Tabel $\mathrm{t}$ significant $0,05 \%=2,101$

Kesimpulan : t hit > t tabel 0,05 hasil cabai per tanaman ternyata berbeda nyata, hipotesis $\mathrm{H}_{0}$ diterima dan hipotesis alternatif HA ditolak.

'Hasil panen pertanaman pada penggunaan paket teknologi intensif ternyata memberikan hasil yang lebih banyak dibandingkan teknologi petani yaitu 89,44 gram dan helai dibanding 47,78 gram. Hal ini disebabkan tanah tempat penelitian sudah diberi pupuk 
kompos dan pupuk susulan yaitu NPK, juga sudah diberi pengapuran, sedangkan cara petani tidak diberi pengapuran.

Kesesuaian lahan untuk tanaman cabai merah ditentukan oleh delapan karakteristik lahan yaitu temperatur udara, ketersediaan air, ketersediaan oksigen (kondisi drainase), media perakaran, retensi hara, toksisitas, bahaya erosi dan penyiapan lahan. Proses fisiologi tanaman cabai merah sangat dipengaruhi oleh unsur-unsur ekologi seperti iklim dan tanah serta proses pembudidayaan ( Tingey dan Steffens, 1991 ).

Untuk mengatasi masalah serangan hama penyakit dengan tetap memperhatikan keamanan produk dan lingkungan, perlu dilakukan upaya-upaya yang baik dan benar dengan mengacu pada SOP dan GAP Salah satu upaya yang dilakukan adalah penanaman cabai merah secara tumpangsari dengan tanaman lain. Tumpangsari dipilih karena merupakan pola tanam yang bisa mereduksi serangan hama pada tanaman utama. Tujuan dari pengkajian ini adalah untuk mengetahui penggunaan sistem tumpangsari sebagai salah satu cara untuk mendapatkan produksi cabai dan beberapa sayuran daun yang bermutu dan aman untuk dikonsumsi serta untuk meningkatkan pendapatan petani melalui optimalisasi pemanfaatan lahan ( Pramudyani,L., Qomariah,R. dan Yassin,M., 2012).

Perbandingan hasil panen tanaman cabai merah antara dua perlakuan yaitu teknologi intensif dan teknologi biasa dapat dilihat pada gambar dibawah ini :

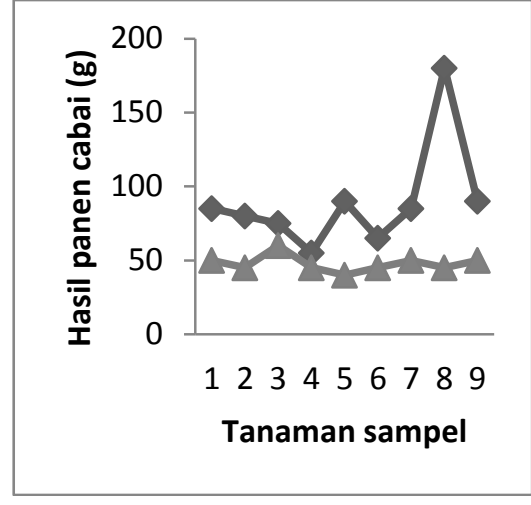

Dari gambar 1. Dapat dilihat bahwa hasil pada setiap tanaman sampel yang diteliti dengan menggunakan teknologi insentif ternyata memberikan hasil panen yang lebih tinggi deibandingkan cara biasa, yaitu rata -rata hasil per batang 89,44 gram , sedangkan cara biasa hanya 47,78 gram. Hal tersebut disebabkan Hasil yang lebih baik ini, dimungkinkan karena dilaksanakannya teknologi budidaya cabai intensif yang standar, yaitu sistem pembudidayaan yang menggunakan masukan (seperti tenaga kerja dan modal) dalam ukuran besar, relatif terhadap satu luas lahan. Untuk efisiensi lahan dan meraih keuntungan yang besar.

Masukan besar diperlukan untuk aplikasi berbagai teknologi pertanian, seperti penggunaan pupuk, peptisida, benih, perawatan, pemanenan. Selain itu, penyiraman juga dilakukan secara terkendali .sehingga memerlukan investasi yang besar. Hasil usaha tani dengan pertanian intensif biasanya sangat tinggi karena didukung oleh teknologi yang didasarkan pada berbagai riset. Hal ini bisa dilakukan asalkan produksi memberikan keuntungan yang besar dan memenuhi target kuantitas dan standar kualitas. Disamping itu tanaman cabai menghendaki perhatian dan perawatan yang lebih keras dan maksimal, mulai dari penanaman sampai panen. 


\section{KESIMPULAN DAN SARAN}

Dari hasil penelitian dapat disimpulkan sebagai berikut;

1. Tinggi tanaman rumput gajah tidak beda nyata tetapi Lain halnya pada jumlah rumpun gajah menunjukan perbedaan nyata. Ternyata paket teknologi memberikan jumlah rumpun tertinggi dibandingan dengan cara biasa.

2. Pada tanaman kunyit Tinggi tanaman dan jumlah daun ternyata sama anatara kedua penerapan paket teknologi dan cara biasa.

3. Tinggi tanaman dan jumlah daun tanaman bawang dayak ternyata lebih tinggi pengaruhnya pada paket teknologi dibandingkan cara biasaq.

4. Pada tinggi tanaman cabai merah menunjukan pengaruh yang sama antara kedua penerapan paket tersebut. Tetapi pada hasil panen cabai merah ternyata lebih banyak hasilnya pada penerapan paket teknologi.

\section{DAFTAR PUSTAKA}

Balitbangtan. 2007. Petunjuk teknis lapang pengelolaan panaman terpadu (PTT) padi sawah irigasi. Badan Penelitian dan Pengembangan Pertanian. Jakarta. 27p.

Balitbangtan. 2008. Panduan umum pengelolaan tanaman terpadu jagung. Badan Penelitian dan Pengembangan Pertanian. Jakarta. 27p.

Cahyaning,R. 2019. Pertumbuhan dan Produksi Tanaman Bawang Sabrang (Eleutherine americana Merr) Terhadap Pemberian Pupuk Kandang Ayam Pada Berbagai Jenis Mulsa . Skripsi .Universitas Muhammadiyah Sumatrera Utara

Harpenas, Asep \& R. Dermawan. 2010. Budidaya Cabai Unggul. Penebar

Swadaya. Jakarta.

Juergen S. Marassing, W. B. Kaunang, F. Dompas dan N. Bawole ( 2013 ) rumput gajah $d$ warf.

Kariyasa, I.K. dan B.M. Sinaga. 2004. Faktor-faktor yang mempengaruhi prilaku pasar jagung di Indonesia. Jurnal Agroekonomi 22(2):167-193. Pusat Penelitian dan Pengembangan Sosial Ekonomi Pertanian. Badan Penelitia dan Pengembangan Pertanian. Departemen Pertanian.

Nurfalach, Devi Rizqi (2010). Budidaya Tanaman Cabai Merah (Capsicum annum L) Di UPTD Pembibitan Tanaman Hortikultura Desa Pakopen Kecamatan Bandungan Kabupaten Semarang Tugas Akhir di Fakultas Pertanian Universitas Sebelas Maret Jurusan/Program Studi DIII Agribisnis Minat Hortikultura dan Arsitektur Pertamanan

Prabaningrum, L \& Moekasan, T 2014, 'Pengelolaan organisme pengganggu tumbuhan pada budidaya cabai merah di dataran tinggi', J. Hort., vol. 24, no. 2, pp. 179-188.

Pramudyani, L., Qomariah, R., dan $\begin{array}{lrr}\text { Yassin, M } & 2012 . \\ \text { Tumpangsari } & \text { Tanaman } \\ \text { Cabai Merah } & \text { Dengan } \\ \text { Bawang Daun } & \begin{array}{r}\text { Menuju } \\ \text { Pertanian }\end{array} & \begin{array}{r}\text { Ramah } \\ \text { Lingkungan. }\end{array} \\ \text { Balai }\end{array}$ 
Pengkajian Teknologi

Pertanian (BPTP) Kalimantan

Selatan Jalan Panglima Batur

Barat 4 Banjarbaru-

Kalimantan Selatan

lelyahya@yahoo.co.id -

081334520136

Prasetyo, Prasetyo and Entang Inoriah,

Sukardjo and Hesti , Pujiwati (2009). Produktivitas Lahan dan NKL pada Tuumpang Sari Jarak Pagar dengan Tanaman Pangan. Akta Agrosia, 12 (1). pp. 51-55. ISSN 1410-3354

Setiawati, W, Sumarni, N, Koesanoriani, Y, Hasyim, A, Uhan, TS \& Sutarya, R 2013, 'Penerapan tehnologi pengendalian hama terpadu pada tanaman cabai merah untuk mitigasi dampak perubahan iklim', J. Hort., vol. 23, no. 2, pp. 174-183.

Syuryawati dan Faesal,2014. Kelayakan Finansial Penerapan Teknologi Budi Daya Jagung pada Lahan Sawah Tadah Hujan. Balai Penelitian Tanaman Serealia Jl. Dr. Ratulangi 274 Maros, Sulawesi Selatan, Indonesia.

Zulkifli AK, Adli Yusuf, Amrizal,T. Iskandar, M. Adil, M. Nasir Ali, Buchari Sulaeman, Roswita, A.Azis, T.M. Fahrizal, Zulkifli Umar, T.Djuanda, 2000 . Rakitan Teknologi Budidaya Cabai Merah. pengkajian SUT Cabai Merah LPTP Banda Aceh

T. Islami dan WH. Utomo,1995. Hubungan tanah, air dan tanaman.Jurnal, IKIP Semarang.

Tingey and steffens. 1991. Potato Glandular Trichomes,
Devensive Activity against Insect Attack. ACS Symposium SeriesVol. 449

ISBN13:

9780841218970eISBN:

9780841213050 American

Chemical Society

Wardhana, W. 2010. Pengaruh waktu tanam terhadap pertumbuhan dan pruduksi pada sistem tanam tumpangsari ubi jalar dan jagung manis. Departemen Agronomi dan Hortikultura Fakultas Pertanian. IPB. 